\title{
Genome-wide association study of periodontal pocketing in Finnish adults
}

Paula Tegelberg ${ }^{1}$, Jussi Miikkael Leppilahti ${ }^{{ }^{*}}$, Atte Ylöstalo ${ }^{1,2,3,4}$, Tellervo Tervonen ${ }^{1,5}$, Johannes Kettunen ${ }^{2,3,4,6}$, Anna Liisa Suominen ${ }^{8,9,10}$ and Pekka Ylöstalo ${ }^{1,3,5,7}$

\begin{abstract}
Background: A genome-wide association study is an analytical approach that investigates whether genetic variants across the whole genome contribute to disease progression. The aim of this study was to investigate genome-wide associations of periodontal condition measured as deepened periodontal pockets ( $\geq 4 \mathrm{~mm}$ ) in Finnish adults.
\end{abstract}

Methods: This study was based on the data of the national Health 2000 Survey (BRIF8901) in Finland and the Northern Finland Birth Cohort 1966 Study totalling 3,245 individuals. The genotype data were analyzed using the SNPTEST v.2.4.1. The number of teeth with deepened periodontal pockets ( $\geq 4 \mathrm{~mm}$ deep) was employed as a continuous response variable in additive regression analyses performed separately for the two studies and the results were combined in a meta-analysis applying a fixed effects model.

Results: Genome-wide significant associations with the number of teeth with $\geq 4 \mathrm{~mm}$ deep pockets were not found at the $p$-level of $<5 \times 10^{-8}$, while in total 17 loci reached the p-level of $5 \times 10^{-6}$. Of the top hits, SNP rs 4444613 in chromosome 20 showed the strongest association $\left(p=1.35 \times 10^{-7}\right)$.

Conclusion: No statistically significant genome-wide associations with deepened periodontal pockets were found in this study.

Keywords: Epidemiologic studies, Genome-wide association study, Periodontal pocket, Periodontitis

\section{Background}

According to the current conception, susceptibility to the initiation and progression of periodontitis depends on the strength of the genetically determined immune response against bacteria [1, 2]. Modifying co-factors associated with periodontitis include age, sex, smoking, diabetes, obesity, and socioeconomic factors [3, 4].

Using a classic twin study design, Michalowicz and his group [5,6] showed that approximately $50 \%$ of the variation in clinically determined adult periodontitis was attributed to genetic variance. A later twin study, which used self-reported data on periodontal condition,

\footnotetext{
${ }^{*}$ Correspondence: jussi.leppilahti@oulu.fi

${ }^{1}$ Research Unit of Oral Health Sciences, Faculty of Medicine, University of Oulu, Oulu, Finland

Full list of author information is available at the end of the article
}

reported lower heritability estimates for periodontitis; $39 \%$ in women and 33\% in men [7]. Overall, heritability seems to be higher for severe early-onset traits and among younger individuals $[2,8]$.

Although the twin studies were crucial in determining the overall role of the genetic component behind periodontitis they could not be used for the identification of the number and location of the susceptibility genes. To achieve the latter goal, two widely used approaches have been used; a candidate gene association study and a genome-wide association study (GWAS). In a recent systematic review and meta-analysis, the authors concluded that up to one-third of periodontitis variance in the population was attributable to genetic factors [2]. In general, lower heritability was reported in studies using 
GWAS design in comparison to twin studies or other family studies [2].

GWAS enables screening of genetic variants across the whole genome linked to a disease under investigation. Unlike the candidate gene studies, in which the selection of target genes is based on their known role in the pathogenesis of the disease, GWAS offers an approach for the determination of novel polymorphisms that is not limited by prior knowledge. A number of studies have investigated genome-wide associations of different periodontitis phenotypes $[2,9,10]$. In terms of the GWA approach in chronic periodontitis, several studies using various case definitions and populations of different ethnic origins have been published $[8,11-22]$. Only a few of these studies reported associations on the level of stringent genome-wide significance level $\left(p\right.$ value $\left.<5 \times 10^{-8}\right)[18$, $20-22]$.

\section{Methods}

In this study, the aim was to investigate genome-wide associations of the number of teeth with deepened periodontal pockets $(\mathrm{PD} \geq 4 \mathrm{~mm}$ ) in 30-65-year old Finnish adults (Fig. 1). We used the data of two studies, the national Health 2000 Survey and the Northern Finland
Birth Cohort 1966 Study (NFBC1966), collected using the following methods:

\section{The Health 2000 survey}

In the Health 2000 Survey, which consisted of a study of persons living in mainland Finland in 2000-2001, a clinical oral health examination was carried out on 6,335 individuals aged 30 years or over [23, 24].

In the clinical oral health examination, dental plaque was measured from three predetermined teeth, on one surface each: from the buccal surface of the most posterior tooth in the upper right quadrant, from the lingual surface of the most posterior tooth in the lower left quadrant, and the labial surface of the lower canine in the lower left quadrant [25]. The presence of plaque was categorized into three categories: no visible plaque (value 1), visible plaque on gingival margins only (value 2 ), or visible plaque also elsewhere (value 3). The mean of these values was used as an individual plaque score in the statistical analyses.

Probing pocket depths were measured using a ballpointed WHO periodontal probe with markings at 3.5 and $5.5 \mathrm{~mm}$. Measurements were taken at four sites per tooth (distal angle on the buccal side, midbuccal, midlingual and mesial angle on the lingual side). Only the

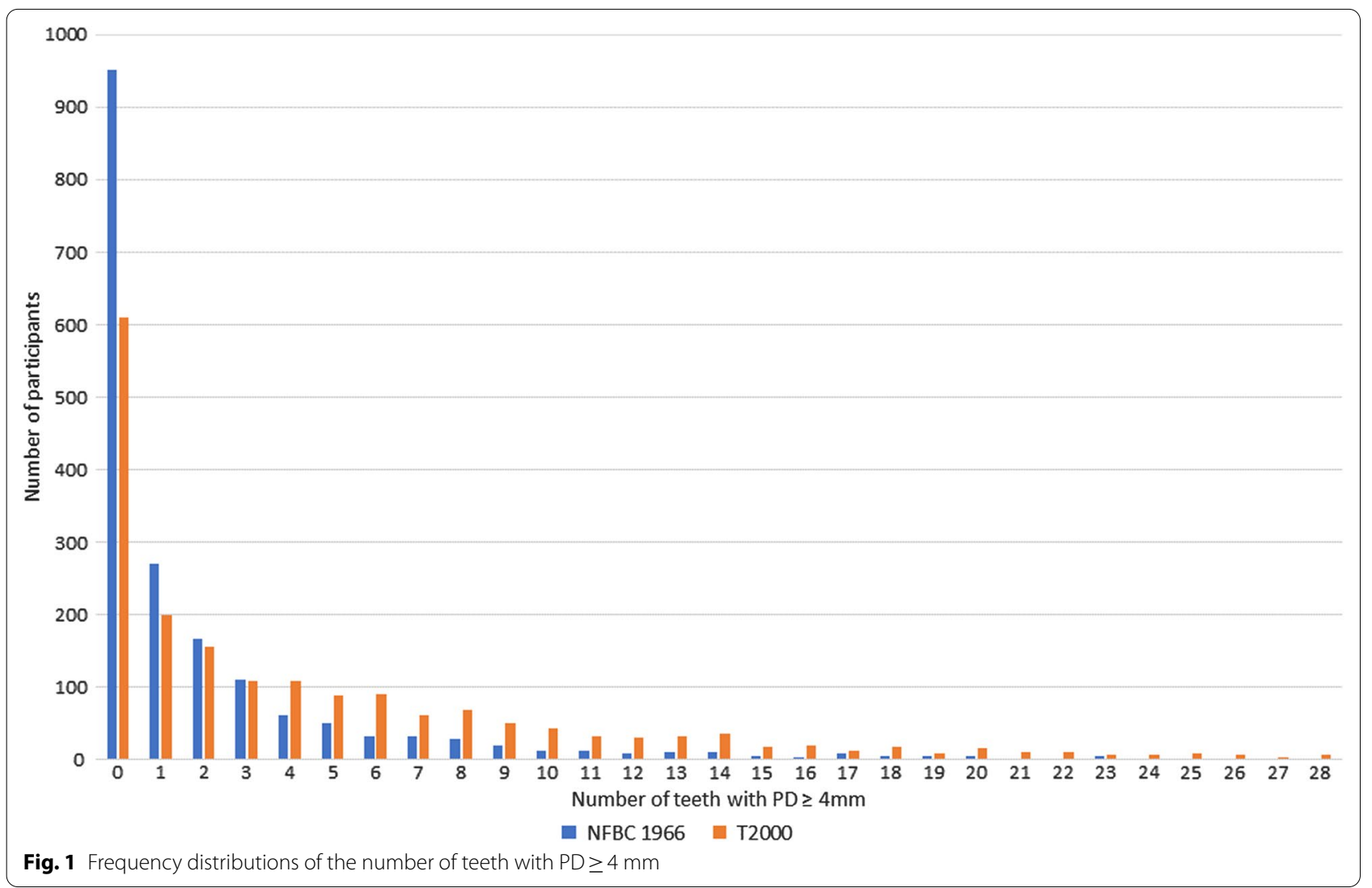


deepest pocket on each tooth was recorded as follows: periodontal pocket $4-5 \mathrm{~mm}$ deep and $\geq 6 \mathrm{~mm}$ deep. A variable, the number of teeth with $\geq 4 \mathrm{~mm}$ deep periodontal pockets, was then created for statistical analyses. Third molars and radices were not included in the periodontal examination.

\section{The NFBC 1966 study}

The NFBC 1966 Study is a life-span cohort study of individuals born in 1966 in the two northernmost provinces in Finland [26]. In 2012-2013, when the subjects were 46 years old, a comprehensive oral health examination was included in the study for the first time. It was carried out on 1,964 persons living in Oulu or within a $100 \mathrm{~km}$ radius from Oulu, the largest city in northern Finland.

In the periodontal examination, plaque was registered from the buccal sites of the teeth as follows: no visible plaque (value 0), plaque when lightly touching the tooth surface by the tip of a periodontal probe (LM 8-520B, Lääkintämuovi, Finland) or visible plaque (value 1). For the statistical analyses, the figures were converted into a percentual plaque score, i.e. percentage of sites with value 1 , to better correspond to the scale used in the Health 2000 Survey (1-3, continuous variable). Probing pocket depths were measured at four sites per tooth (mesiobuccal, midbuccal, distobuccal and midoral). The probing force was calibrated for every subject using a letter scale (corresponding to $25 \mathrm{~g}$ ). The number of teeth with $\geq 4 \mathrm{~mm}$ deep periodontal pockets was calculated for the statistical analyses. Wisdom teeth and radices were excluded from the periodontal examination.

Subjects with diabetes mellitus (T1DM or T2DM) and rheumatoid arthritis were excluded from both surveys based on a health interview of the Health 2000 Survey and an oral glucose tolerance test (screened T2DM) and questionnaire data on general health of the NFBC 1966 Study. In addition, we excluded subjects over the age of 65 from the Health 2000 Survey. In both surveys, data on smoking were collected using data of the health interview and the questionnaire and categorized as non-smoker or smoker (including both former and current smokers).

The basic characteristics of altogether 3,906 participants in the two surveys are presented in Table 1.

\section{Genotyping}

The Health 2000 DNA samples were genotyped using Illumina Humanhap $610 \mathrm{k}$ array and the NFBC 1966 using Illumina Humanhap $310 \mathrm{k}$ array. The genotypes were called with Illuminus software and imputed to $1000 \mathrm{~g}$ reference (phase $1 \mathrm{v} 3$ ) using IMPUTE2 software (http://mathgen.stats.ox.ac.uk/impute/impute_v2.html). The following exclusion criteria were used in the quality control of original datasets: NFBC 1966: Call rate in the
Table 1 Basic characteristics of the study populations

\begin{tabular}{lll}
\hline & $\begin{array}{l}\text { Health 2000 Survey } \\
(\mathbf{N}=\mathbf{2 0 6 8})\end{array}$ & $\begin{array}{l}\text { NFBC 1966 Study } \\
(\mathbf{N}=1838)\end{array}$ \\
\hline $\begin{array}{l}\text { Age, years } \\
\text { Sex }\end{array}$ & $30-65$ & 46 \\
$\quad$ Female & & \\
$\quad$ Male & 51.5 & 53.5 \\
Smoking status & 48.5 & 46.5 \\
$\quad$ Non-smoker & 70.6 & \\
$\quad$ Current smoker & 29.4 & 68.9 \\
$\quad$ Missing data & 0.0 & 21.4 \\
Plaquec ${ }^{c}$ mean (SD) & $1.8(0.7)^{\mathrm{a}}$ & 9.7 \\
Number of teeth with & $4.7(5.9)$ & $1.4(0.6)^{\mathrm{b}}$ \\
PD $\geq 4$ mm ${ }^{\mathrm{d}}$, mean (SD) & & $2.0(3.9)$ \\
\hline
\end{tabular}

SD standard deviation, $\mathrm{PD}$ pocket depth

${ }^{a}$ The mean of maximum plaque values $(1,2$ or 3$)$

${ }^{\mathrm{b}}$ Scale 1-3

' Data available of 1560 participants in the Health 2000 Survey and of 1809 participants in the NFBC 1966 Study

${ }^{d}$ Data available of 1860 participants in the Health 2000 Survey and of 1820 participants in the NFBC 1966 Study

final sample was $<95 \%$, P value of Hardy-Weinberg Equilibrium $(\mathrm{HWE})<0.0001$, and $\mathrm{MAF}<1 \%$; Health 2000: Call rate $<95 \%, \mathrm{HWE}<1 \times 10^{-6}, \mathrm{MAF}<1 \%$. The more detailed information of sample preparation, genotyping and quality control have been thoroughly described in the first original GWA studies of the Health 2000 Survey [27] and the NFBC1966 Study [28].

\section{Statistical analysis}

The SNP-TEST v 2.4.1, which is a test for the analysis of SNP association in GWAS (https://mathgen.stats.ox.ac. uk/genetics_software/snptest/snptest_v2.4.1.html), was used. Variants were filtered prior to the meta-analysis by minor allele frequency (MAF; $<0.01$ ), additive model information measure $(<0.7)$ and $\mathrm{SE}>0$.

Genome-wide association studies were performed separately for the two studies using additive regression models adjusted for population stratification, age, sex, smoking, and plaque. The first ten principal components were used in the analyses for population stratification. The number of teeth with deepened periodontal pockets $(\geq 4 \mathrm{~mm})$ was used as a continuous outcome variable.

The results were combined in a meta-analysis applying a fixed effects model and using GWAMA, a software for performing genome-wide association meta-analysis (https://www.geenivaramu.ee/en/tools/gwama). Genomic control was enabled during meta-analysis. Manhattan plots (Fig. 2) were created using the qqman package for $\mathrm{R}$ software (https://cran.r-project.org/web/ packages/qqman/index.html). 

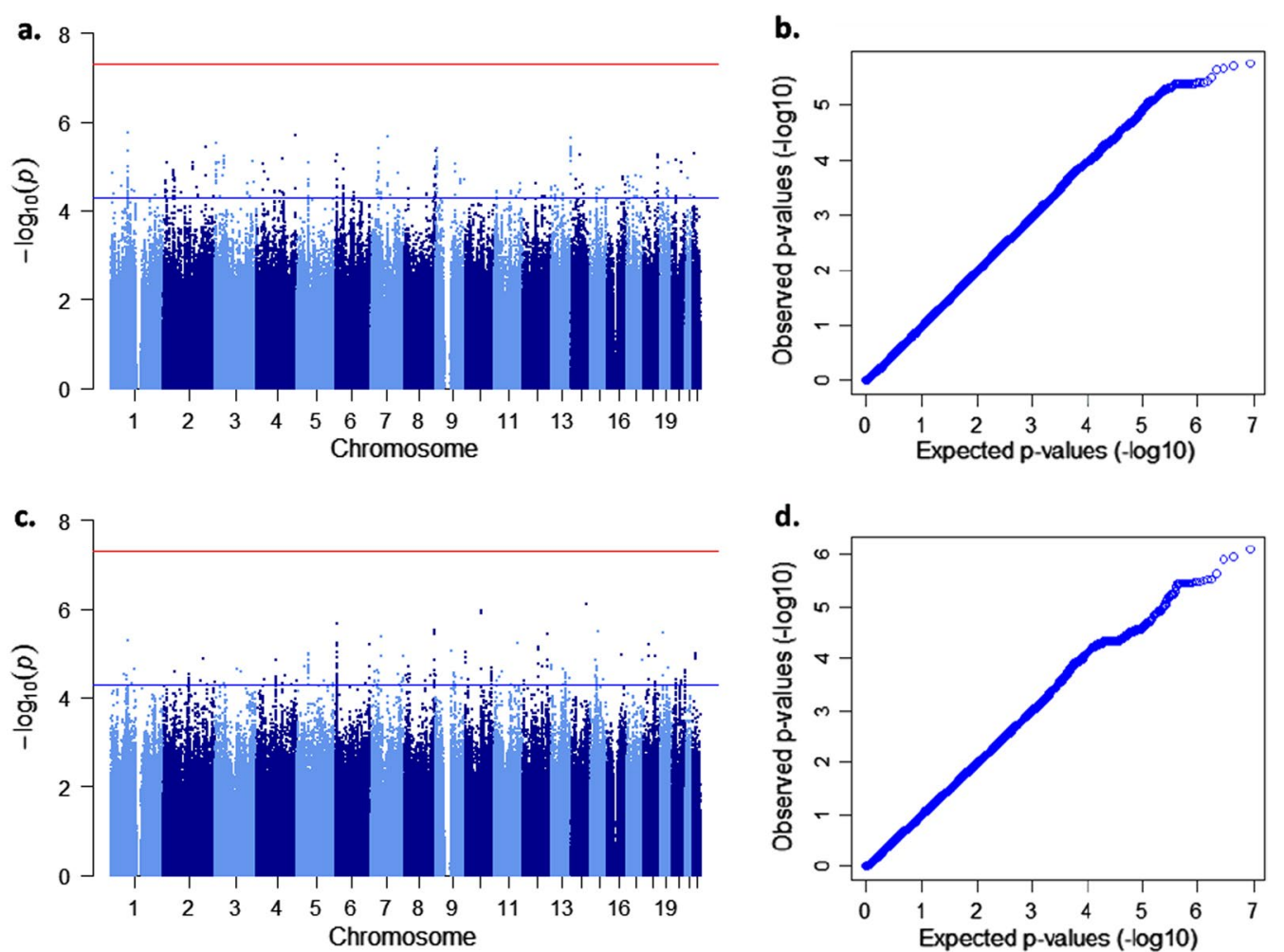

d.
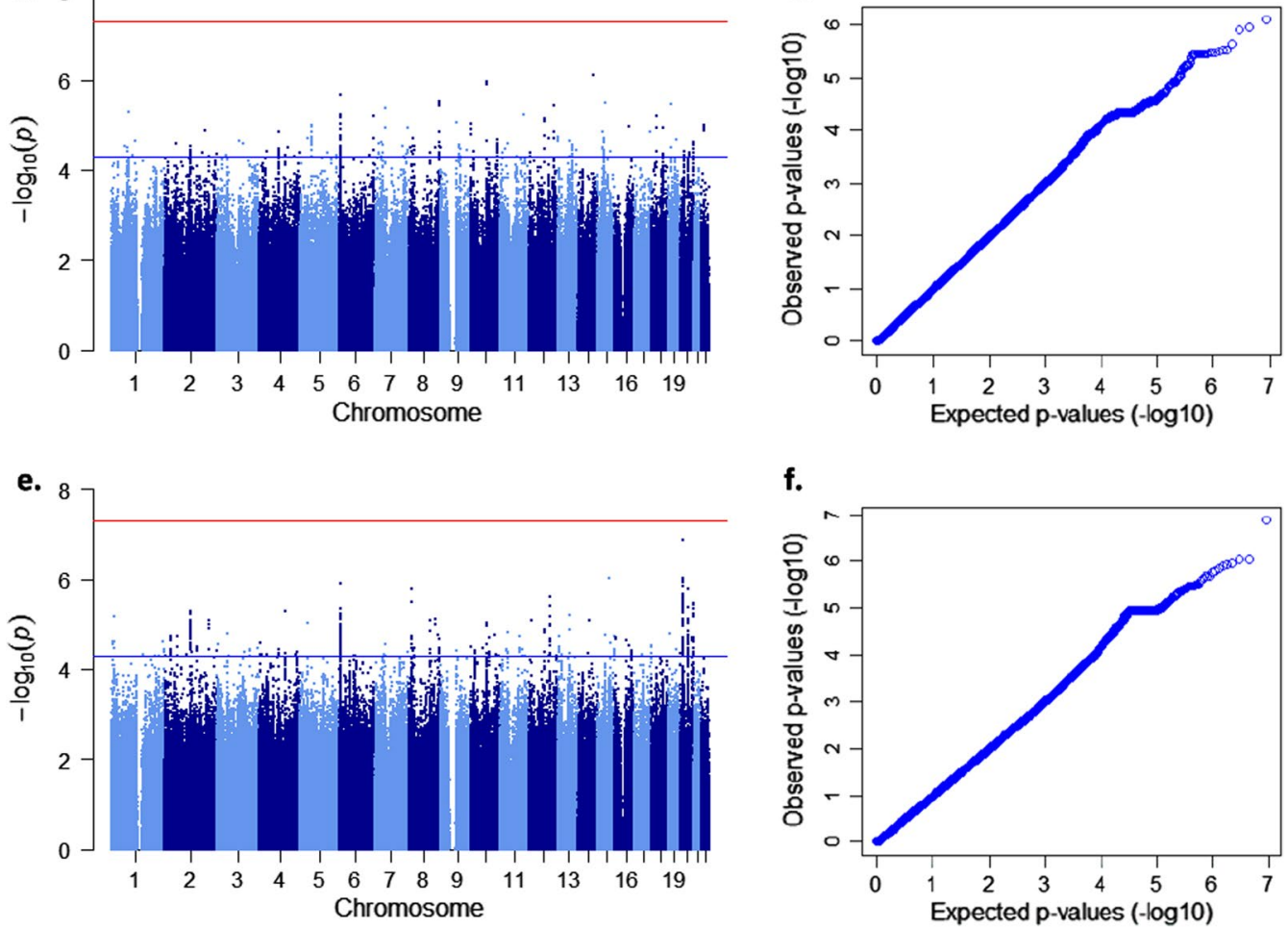

Fig. 2 Manhattan and quantile-quantile plots showing GWAS results for the quantitative trait with three different adjustments. Manhattan (a, $\mathbf{c}$ e) and quantile-quantile $(\mathbf{b}, \mathbf{d}, \mathbf{f})$ plots related to the same adjustments are given side by side: $\mathbf{a}, \mathbf{b}$ age, sex, and the first ten principal components. The genomic inflation factor lambda is 0.99 for NFBC66 and 1.01 for T2000 data. c, d: age, sex, smoking, and the first ten principal components. The genomic inflation factor lambda is 0.98 for NFBC66 and 0.99 for T2000 data. e, $\mathbf{f}$ age, sex, smoking, plaque, and the first ten principal components. The genomic inflation factor lambda is 0.98 for NFBC66 and 0.99 for T2000 data. Red lines indicate genome-wide signifcance level, $p<5 \times 10^{-8}$

While a total of 3245 subjects were included in the final age- and sex-adjusted analyses the fully adjusted analyses were based on the data of 2650 subjects. The threshold for statistical significance on the genomewide level was defined as $p$ value $<5 \times 10^{-8}$. Another threshold was set at $\mathrm{p}$-level of $5 \times 10^{-6}$ for reporting so called "suggestive" associations.

\section{Results}

In the national Health 2000 Survey and the NFBC 1966 Study, $48.5 \%$ and $46.5 \%$ of the participants were males, and $70.6 \%$ and $68.9 \%$ non-smokers, respectively (Table 1 ). The mean number of teeth with $\geq 4 \mathrm{~mm}$ deep periodontal pockets was 4.7 (SD 5.9) in the Health 2000 Survey and 2.0 (SD 3.9) in the NFBC 1966 Study (Table 1). 
While no significant genome-wide associations ( $p$ value $<5 \times 10^{-8}$ ) with the number of teeth with $\geq 4 \mathrm{~mm}$ deep pockets were found in this study 17 loci, in total, reached the $p$-level of $5 \times 10^{-6}$ in the analyses (Fig. 2, Table 2). We used three different sets of co-variates in the analyses and discovered that the SNP with the lowest $p$ value, rs4444613 in chromosome $20\left(p=1.35 \times 10^{-7}\right)$, was found when a full set of co-variates including smoking and plaque was used (Table 2). We also observed that different top hits emerged when different co-variates were used. From beyond the top hits, only one SNP, rs200392355, emerged twice; in the fully adjusted analysis $\left(1.22 \times 10^{-6}\right)$ and when adjusting for age, sex, smoking and the first ten principal components $\left(2.23 \times 10^{-6}\right)$ (Table 2). There was not any observable sign of population stratification in the qq-plots. Qq-plots and respective lambda values are given in Fig. 2.

\section{Discussion}

In this study, which was the first GWAS on periodontal condition in the Finnish adult population, no statistically significant associations were found. However, in total 17 SNPs showed associations at the p-level $<5 \times 10^{-6}$; of these rs4444613 was the stongest one $\left(p=1.35 \times 10^{-7}\right)$. In line with a number of earlier studies, which required statistical evidence of association at a $p$ value level of $<5 \times 10^{-8}$, we conclude that there were no associated genetic loci with the presence of deepened periodontal pockets $(\geq 4 \mathrm{~mm})$ in this population. It is likely that a larger sample size would be required to uncover genetic variation underlying the periodontal condition in this population.

In terms of earlier GWAS on chronic periodontitis, only a few loci have reached the genome-wide significance and hardly any of the findings have been replicated in an independent sample. Sanders et al. (2017) found an association with a rare variant of TSNAXDISC1 noncoding mRNA (lead signal: rs149133391, MAF: 0.011) in a large population of Hispanics and Latinos and the variant was replicated in an African-American but not in a European-American sample. However, the finding should be interpreted with caution due to the rarity of the variant and small sample size in the replication data. In a genetically isolated population in Italy, four SNPs in the $E F C A B 4 B$ gene (rs242016, rs242014, rs10491972, and rs242002) were found to be significantly associated with localized periodontitis but the findings have not been replicated so far [20].

Different variants of SIGLEC5 were found as shared risk loci in studies combining AgP and severe CP cases in German, Dutch and Turkish populations [19], and rediscovered in a meta-analysis of German and Dutch AgP, and European-American and German CP cases
[21]. In addition, significant variants for DEF1A3 (rs2978951, rs2738058), MTND1P5 (rs16870060), and LOC107984137 near the SHISA9 gene (rs729876) were found in these studies combining CP and AgP cases [19, 21]. From these genes, only SIGLEC5 related variants have been found in later studies. Shungin et al. (2019) also found a single-risk locus of SIGLEC5 (rs12461706, $p=3.9 \times 10^{-9}$ ) by combining a questionnaire-based proxy phenotype of "loose teeth" (referring to severe periodontitis) with clinically verified periodontitis data. Also, the association of SIGLEC5 related variants with severe periodontitis of rapid progression phenotype, stage III$\mathrm{IV}$, grade $\mathrm{C}$ according to the new periodontitis classification, was recently re-discovered in a pathway analysis but not in GWAS by de Coo et al. (2021).

Overall, the evidence for the genetic basis of CP based on the GWAS approach has so far been only modest. Moreover, the studies where SNPs exceeded the threshold of a significant association reported no SNPs in common, so there has been hardly any overlap in the genetic variants among the numerous suggestive associations reported to date $[11,13,14]$. In similar fashion, the 17 suggestive SNPs $\left(p<5 \times 10^{-6}\right)$ found in this study were not found in the GWAS catalog (https://www.ebi.ac.uk/ gwas/), which lists in total 154 suggestive SNPs associated with periodontitis (published before 31th of August 2021). Neither were the previously reported significant SIGLEC5 associated SNPs (rs4284742, rs11084095, rs12461706) linked with periodontal pocketing in our analysis $(p>0.3)$. It has also appeared that the significant gene variants linked with the susceptibility to periodontitis using the candidate gene approach [1] turned out to be non-significant in the GWAS approaches $[8,13$, 14]. The main problem in the previous studies and also within our study is the limited sample size to uncover the genetic background of tens or hundreds of probable periodontal risk genes/ loci with low independent effect size and possible interactions with other risk factors.

Although the search for genome-wide significant variants has not produced consistent results, it does not mean that such variants do not exist. The stringent GWAS significance level minimizes the risk of false positives (type I error). However, in this study and other previous GWAS of periodontitis, it is evident that causative variants (with minor effect size) were classified statistically non-significant (type II error) because lack of statistical power. The omnigenic model/hypothesis of complex traits proposes that there is a huge number of common variants with a very small effect and, possibly, a small number of rare variants with moderate or larger effects. In GWA studies in periodontology, there are hardly any replicated variants with even moderate effect size $(\mathrm{OR}<1.5)$ and it seems more likely that genetic risk 


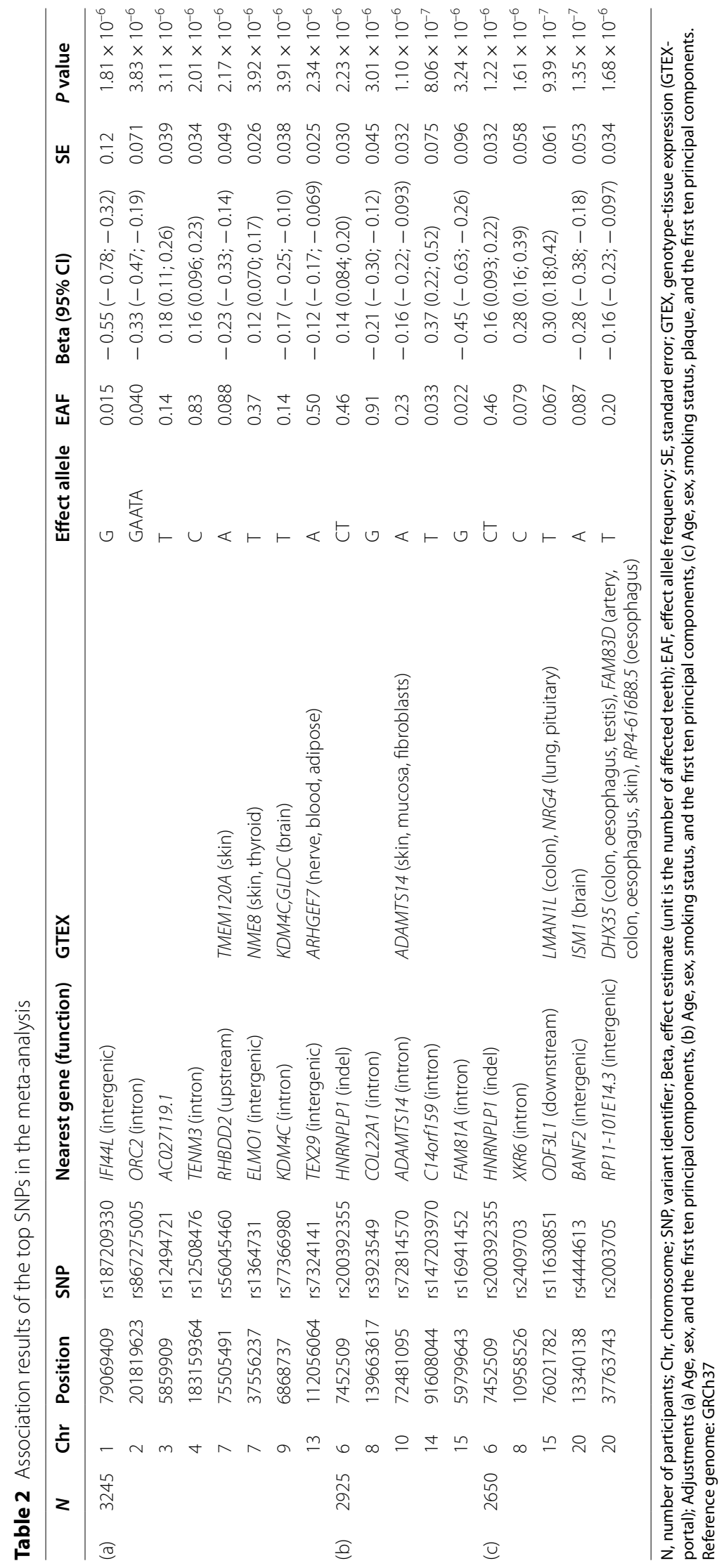


of periodontitis is influenced by hundreds or thousands of genes with very small effect size [29, 30]. Apart from the variation in the DNA sequence, there may also be changes in gene expression. Growing evidence exists that epigenetic changes, which are not captured by GWASs, play a role in the inflammatory pathways of periodontitis through activation or inactivation of genes [31].

Teumer et al. (2013) reported that different top SNPs emerged for different case definitions of periodontitis in the same population [8]. The fact that various definitions for periodontitis were used partly explains the heterogeneity between the results of earlier genetic studies. Commonly used measures for periodontal tissue destruction include periodontal attachment level, probing pocket depth, the latter two combined, and radiographic bone loss. In this study, we used the number of teeth with periodontal probing depth $\geq 4 \mathrm{~mm}$ as a surrogate measure of existing inflammatory periodontal condition. A disadvantage of the outcome variable is that it does not take into account possible gingival retraction, which is common in older individuals, and therefore may underestimate the severity of periodontitis in the population. Due to lack of data on attachment level (Health 2000 Survey, NFBC1966 Study) and alveolar bone level (Health 2000 Survey) we could not identify true periodontitis cases and, instead used the number of teeth with deepened periodontal pockets $(\mathrm{PD} \geq 4 \mathrm{~mm})$ as a continuous outcome variable. The advantage of the continuous variable is that it comprises and utilizes information of the extent of periodontal disease. Additional advantage is that it reduces the possibility of misclassification of periodontal condition when compared with a situation where a dichotomous outcome is used.

The new periodontitis classification system, based on stages of clinical attachment loss and treatment complexity, and grades of disease progression rate [32] may help in standardizing periodontitis phenotypes. However, the age of the disease onset is not included in the new classification, which poses challenges to identify cases with high genetic risk, i.e. severe cases with rapid disease progression or patients with disproportionally rapid disease progression. Additional challenge is that the category to which those genetically susceptible periodontal patients often belong (Stage III-IV, Grade C) is the same to which the patients who are heavy smokers or patients with poorly controlled diabetes often belong.

To increase homogeneity of study population we excluded individuals with diabetes mellitus and rheumatoid arthritis due to their links with periodontitis [33, 34]. In addition, to reduce the effect of tooth loss in the older part of the population, the study population was restricted to subjects under 66 years of age in the Health 2000 Survey. In light of earlier studies, which have shown that, compared to older age groups, heritability has a stronger effect on periodontal condition in subjects aged $<65$ years [7] or $\leq 60$ years [8] the latter restriction is relevant.

Sex, age and smoking, but not dental plaque, are commonly controlled for in GWAS. In this study, we controlled also for the presence of dental plaque, which can be justified based on previous studies where dental plaque has consistently been associated with gingival inflammation, disease progression, treatment failure, and disease recurrence [35-37]. Visible dental plaque and the number of deepened periodontal pockets has also been shown to correlate within the Health 2000 data [38]. The above periodontal disease determinants were controlled for in the analyses by conducting three different modellings in a step-wise manner. It is worth noting that different variants were found depending on the set of used covariates (Table 2). It is assumed in GWAS that these disease determinants are equally distributed in the categories of explanatory variables (ie. SNPs) and are therefore not confounding factors. However, adjustments for these factors increase statistical power by reducing residual variance.

\section{Conclusion}

This study was the first GWAS on periodontal condition in the Finnish adult population based on the meta-analysis of two Finnish cohorts. While the results of the metaanalysis showed no significant genome-wide associations with deepened periodontal pockets ( $\geq 4 \mathrm{~mm}$ ), 17 SNPs were found that can be tested in future studies using larger sample sizes.

\section{Abbreviations}

CP: Chronic periodontitis; AgP: Aggressive periodontitis; GWA: Genome-wide association; GWAS: Genome-wide association study; NFBC 1966: Northern Finland Birth Cohort 1966; SNP: Single nucleotide polymorphism; TSNAXDISC1: Translin-associated factor X Disrupted in schizophrenia 1; EFCAB4B: EF-hand calcium binding domain 4B; SIGLEC5: Sialic Acid Binding lg Like Lectin 5; DEF1A3: Defensin alpha 1-3; MTND1P5: MT-ND1 pseudogene 5; SHISA9: Shisa family member 9; GLT6D1: Glycosyltransferase 6 domain containing 1.

\section{Acknowledgements \\ We want to thank professor Aarno Palotie for his help in initiating this research project and for his valuable comments during the project. We thank all Health 2000 Survey and NFBC 1966 study members and researchers who participated in the study. We also wish to acknowledge the work of NFBC project center.}

\section{Authors' contributions}

PY, AY, TT, PT, JK and ALS conceptualised and designed the study. AY, JK, and ALS designed and performed the statistical analysis. PT, JL, PY, ALS and TT reviewed literature, and prepared and edited the manuscript. All authors read and approved the final manuscript.

\section{Funding}

NFBC 1966 31y follow-up study received financial support from University of Oulu Grant No. 65354, Oulu University Hospital Grant No. 2/97, 8/97, Ministry of Health and Social Affairs Grant no. 23/251/97, 160/97, 190/97, National 
Institute for Health and Welfare, Helsinki Grant no. 54121, Regional Institute of Occupational Health, Oulu, Finland Grant no. 50621, 54231.

NFBC1966 46y follow-up study received financial support from University of Oulu Grant No. 24000692, Oulu University Hospital Grant No. 24301 140, ERDF European Regional Development Fund Grant no. 539/2010 A31592. Health 2000 Survey was organized by the National Institute of Health and Welfare (THL) [formerly the National Public Health Institute (KTL) of Finland], (http:// www.terveys2000.fi) and partly supported by the Finnish Dental Society ApolIonia and the Finnish Dental Association. The first author (PT) was financially supported by the Finnish Dental Society Apollonia with a grant. The work was supported through The Sigrid Juselius Foundation (JK), funds from the Academy of Finland [Grant Numbers 297338 (JK) and 307247 (JK), 326189 (JL)] and Novo Nordisk Foundation [Grant Number NNF170C0026062] (JK).

\section{Availability of data and materials}

NFBC 1966 data is available from the University of Oulu, Infrastructure for Population Studies. Permission to use the data can be applied for research purposes via electronic material request portal. In the use of data, we follow the EU general data protection regulation (679/2016) and Finnish Data Protection Act. The use of personal data is based on cohort participant's written informed consent at his/her latest follow-up study, which may cause limitations to its use. Please, contact NFBC project center (NFBCprojectcenter@oulu. fi) and visit the cohort website (http://www.oulu.fi/nfbc) for more information. Health 2000 data that support the findings of this study are available from the Finnish Institute for Health and Welfare. However, restrictions apply to the availability of these data, which were used under license for the current study, and are therefore not publicly available. Nevertheless, data are available from the authors upon reasonable request and with permission from the NFBC and the Finnish Institute for Health and Welfare.

\section{Declarations}

\section{Ethics approval and consent to participate}

The study was conducted in accordance with the principles of the Helsinki declaration. Participation in the Health 2000 Survey and NFBC 1966 Study was voluntary. The participants provided informed written consent for the studies. The Ethical Committee of Northern Ostrobothnia Hospital District (74/2011) and the Ethical Committee for Research in Epidemiology and Public Health at the Hospital District of Helsinki and Uusimaa (5/2000) approved the studies.

\section{Consent for publication}

Not applicable.

\section{Competing interests}

The authors declare that they have no competing interests.

\section{Author details}

${ }^{1}$ Research Unit of Oral Health Sciences, Faculty of Medicine, University of Oulu, Oulu, Finland. ${ }^{2}$ Computational Medicine, Faculty of Medicine, University of Oulu, Oulu, Finland. ${ }^{3}$ Center for Life Course Health Research, Faculty of Medicine, University of Oulu, Oulu, Finland. ${ }^{4}$ Biocenter Oulu, University of Oulu, Oulu, Finland. ${ }^{5}$ Medical Research Center, Oulu University Hospital and University of Oulu, Oulu, Finland. ${ }^{6}$ National Institute for Health and Welfare, Helsinki, Finland. ${ }^{7}$ Department of Oral and Maxillofacial Surgery, Oulu University Hospital, Oulu, Finland. ${ }^{8}$ Institute of Dentistry, University of Eastern Finland, Kuopio, Finland. ${ }^{9}$ Department of Oral and Maxillofacial Surgery, Kuopio University Hospital, Kuopio, Finland. ${ }^{10}$ Department of Public Health and Welfare, National Institute for Health and Welfare, Helsinki, Finland.

Received: 23 March 2021 Accepted: 9 November 2021 Published online: 30 November 2021

\section{References}

1. Laine ML, Crielaard W, Loos BG. Genetic susceptibility to periodontitis. Periodontol 2000. 2012;58(1):37-68.

2. Nibali L, Bayliss-Chapman J, Almofareh SA, Zhou Y, Divaris K, Vieira AR. What is the heritability of periodontitis? A systematic review. J Dent Res. 2019;98(6):632-41.
3. Borrell LN, Papapanou PN. Analytical epidemiology of periodontitis. J Clin Periodontol. 2005;32(Suppl 6):132-58.

4. Genco RJ, Borgnakke WS. Risk factors for periodontal disease. Periodontol 2000. 2013;62(1):59-94.

5. Michalowicz BS, Aeppli DP, Kuba RK, Bereuter JE, Conry JP, Segal NL, Bouchard TJ, Pihlstrom BL. A twin study of genetic variation in proportional radiographic alveolar bone height. J Dent Res. 1991;70(11):1431-5.

6. Michalowicz BS, DiehI SR, Gunsolley JC, Sparks BS, Brooks CN, Koertge TE, Califano JV, Burmeister JA, Schenkein HA. Evidence of a substantial genetic basis for risk of adult periodontitis. J Periodontol. 2000;71(11):1699-707.

7. Mucci LA, Bjorkman L, Douglass CW, Pedersen NL. Environmental and heritable factors in the etiology of oral diseases-a population-based study of Swedish twins. J Dent Res. 2005;84(9):800-5.

8. Teumer A, Holtfreter B, Volker U, Petersmann A, Nauck M, Biffar R, Volzke $\mathrm{H}$, Kroemer HK, Meisel P, Homuth G, Kocher T. Genome-wide association study of chronic periodontitis in a general German population. J Clin Periodontol. 2013:40(11):977-85.

9. Schaefer AS. Genetics of periodontitis: discovery, biology, and clinical impact. Periodontol 2000. 2018;78(1):162-73.

10. de Coo A, Cruz R, Quintela I, Herrera D, Sanz M, Diz P, Rodriguez Grandio S, Vallcorba N, Ramos I, Oteo A, Serrano C, Esmatges A, Enrile F, Mateos L, Garcia R, Alvarez-Novoa P, Noguerol B, Zabalegui I, Blanco-Moreno J, Alonso A, Lorenzo R, Carracedo A, Blanco J. Genome-wide association study of stage III/IV grade C periodontitis (former aggressive periodontitis) in a Spanish population. J Clin Periodontol. 2021;48(7):896-906.

11. Divaris K, Monda KL, North KE, Olshan AF, Reynolds LM, Hsueh WC, Lange EM, Moss K, Barros SP, Weyant RJ, Liu Y, Newman AB, Beck JD, Offenbacher $\mathrm{S}$. Exploring the genetic basis of chronic periodontitis: a genome-wide association study. Hum Mol Genet. 2013;22(11):2312-24.

12. Feng $P$, Wang $X$, Casado PL, Kuchler EC, Deeley K, Noel J, Kimm H, Kim JH, Haas AN, Quinelato V, Bonato LL, Granjeiro JM, Susin C, Vieira AR. Genome wide association scan for chronic periodontitis implicates novel locus. BMC Oral Health. 2014;14:84-84

13. Rhodin K, Divaris K, North KE, Barros SP, Moss K, Beck JD, Offenbacher S. Chronic periodontitis genome-wide association studies: gene-centric and gene set enrichment analyses. J Dent Res. 2014;93(9):882-90.

14. Shaffer JR, Polk DE, Wang X, Feingold E, Weeks DE, Lee MK, Cuenco KT, Weyant RJ, Crout RJ, McNeil DW, Marazita ML. Genome-wide association study of periodontal health measured by probing depth in adults ages 18-49 years. G3 Bethesda. 2014;4(2):307-14.

15. Hong KW, Shin MS, Ahn YB, Lee HJ, Kim HD. Genomewide association study on chronic periodontitis in Korean population: results from the Yangpyeong health cohort. J Clin Periodontol. 2015;42(8):703-10.

16. Shimizu S, Momozawa Y, Takahashi A, Nagasawa T, Ashikawa K, Terada Y, Izumi Y, Kobayashi H, Tsuji M, Kubo M, Furuichi Y. A genome-wide association study of periodontitis in a Japanese population. J Dent Res. 2015;94(4):555-61.

17. Kasbohm E, Holtfreter B, Volker U, Petersmann A, Samietz S, Biffar R, Volzke H, Meisel P, Kacprowski T, Homuth G, Kocher T, Teumer A. Exome variant analysis of chronic periodontitis in 2 large cohort studies. J Dent Res. 2017;96(1):73-80.

18. Sanders AE, Sofer T, Wong Q, Kerr KF, Agler C, Shaffer JR, Beck JD, Offenbacher S, Salazar CR, North KE, Marazita ML, Laurie CC, Singer RH, Cai J, Finlayson TL, Divaris K. Chronic periodontitis genome-wide association study in the hispanic community health study/study of latinos. J Dent Res. 2017;96(1):64-72.

19. Munz M, Willenborg C, Richter GM, Jockel-Schneider Y, Graetz C, Staufenbiel I, Wellmann J, Berger K, Krone B, Hoffmann P, van der Velde N, Uitterlinden AG, de Groot LCPGM, Sawalha AH, Direskeneli H, SaruhanDireskeneli G, Guzeldemir-Akcakanat E, Keceli HG, Laudes M, Noack B, Teumer A, Holtfreter B, Kocher T, Eickholz P, Meyle J, Doerfer C, Bruckmann C, Lieb W, Franke A, Schreiber S, Nohutcu RM, Erdmann J, Loos BG, Jepsen S, Dommisch H, Schaefer AS. A genome-wide association study identifies nucleotide variants at SIGLEC5 and DEFA1A3 as risk loci for periodontitis. Hum Mol Genet. 2017;26(13):2577-88.

20. Bevilacqua L, Navarra CO, Pirastu N, Lenarda RD, Gasparini P, Robino A. A genome-wide association study identifies an association between variants in EFCAB4B gene and periodontal disease in an Italian isolated population. J Periodontal Res. 2018;53(6):992-8. 
21. Munz M, Richter GM, Loos BG, Jepsen S, Divaris K, Offenbacher S, Teumer A, Holtfreter B, Kocher T, Bruckmann C, Jockel-Schneider Y, Graetz C, Ahmad I, Staufenbiel I, van der Velde N, Uitterlinden AG, de Groot LCPGM, Wellmann J, Berger K, Krone B, Hoffmann P, Laudes M, Lieb W, Franke A, Erdmann J, Dommisch H, Schaefer AS. Meta-analysis of genome-wide association studies of aggressive and chronic periodontitis identifies two novel risk loci. Eur J Hum Genet. 2019;27(1):102-13.

22. Shungin D, Haworth S, Divaris K, Agler CS, Kamatani Y, Keun Lee M, Grinde K, Hindy G, Alaraudanjoki V, Pesonen P, Teumer A, Holtfreter B, Sakaue S, Hirata J, Yu YH, Ridker PM, Giulianini F, Chasman DI, Magnusson PKE, Sudo T, Okada Y, Volker U, Kocher T, Anttonen V, Laitala ML, Orho-Melander M, Sofer T, Shaffer JR, Vieira A, Marazita ML, Kubo M, Furuichi Y, North KE, Offenbacher S, Ingelsson E, Franks PW, Timpson NJ, Johansson I. Genome-wide analysis of dental caries and periodontitis combining clinical and self-reported data. Nat Commun. 2019;10(1):2773-81.

23. Aromaa, A. \& Koskinen, S: Health and functional capacity in Finland. Baseline results of the Health 2000 Health Examination Survey. Publications of the National Public Health Institute B12/2004 2004.

24. Heistaro S: Methodology Report. Health 2000 Survey. Publications of the National Public Health Institute B26/2008 2008.

25. Silness J, Loe H. Periodontal disease in pregnancy. li. Correlation between oral hygiene and periodontal condtion. Acta Odontol Scand. 1964;22:121-35

26. University of Oulu: Northern Finland Birth Cohort 1966, University of Oulu, http://urn.fi/urn:nbn:fi:att:bc1 e5408-980e-4a62-b899-43bec37552 43.

27. Heid IM, Jackson AU, Randall JC, et al. Meta-analysis identifies 13 new loci associated with waist-hip ratio and reveals sexual dimorphism in the genetic basis of fat distribution. Nat Genet. 2010;42(11):949-60.

28. Sabatti C, Service SK, Hartikainen AL, Pouta A, Ripatti S, Brodsky J, Jones CG, Zaitlen NA, Varilo T, Kaakinen M, Sovio U, Ruokonen A, Laitinen J, Jakkula E, Coin L, Hoggart C, Collins A, Turunen H, Gabriel S, Elliot P, McCarthy MI, Daly MJ, Jarvelin MR, Freimer NB, Peltonen L. Genome-wide association analysis of metabolic traits in a birth cohort from a founder population. Nat Genet. 2009;41(1):35-46.

29. Wray NR, Wijmenga C, Sullivan PF, Yang J, Visscher PM. Common disease is more complex than implied by the core gene omnigenic model. Cell. 2018;173(7):1573-80.

30. Boyle EA, Li YI, Pritchard JK. An expanded view of complex traits: from polygenic to omnigenic. Cell. 2017;169(7):1177-86.

31. Larsson L, Castilho RM, Giannobile WV. Epigenetics and its role in periodontal diseases: a state-of-the-art review. J Periodontol. 2015;86(4):556-68.

32. Tonetti MS, Greenwell H, Kornman KS. Staging and grading of periodontitis: framework and proposal of a new classification and case definition. $J$ Periodontol. 2018:89(Suppl 1):S159-72.

33. Sanz M, Ceriello A, Buysschaert M, Chapple I, Demmer RT, Graziani F, Herrera D, Jepsen S, Lione L, Madianos P, Mathur M, Montanya E, Shapira $L$, Tonetti M, Vegh D. Scientific evidence on the links between periodontal diseases and diabetes: Consensus report and guidelines of the joint workshop on periodontal diseases and diabetes by the International Diabetes Federation and the European Federation of Periodontology. J Clin Periodontol. 2018:45(2):138-49.

34. Araujo VM, Melo IM, Lima V. Relationship between periodontitis and rheumatoid arthritis: review of the literature. Mediators Inflamm. 2015;2015:259074.

35. Ramseier CA, Anerud A, Dulac M, Lulic M, Cullinan MP, Seymour GJ, Faddy MJ, Burgin W, Schatzle M, Lang NP. Natural history of periodontitis: disease progression and tooth loss over 40 years. J Clin Periodontol. 2017;44(12):1182-91.

36. Lertpimonchai A, Rattanasiri S, Arj-Ong Vallibhakara S, Attia J, Thakkinstian A. The association between oral hygiene and periodontitis: a systematic review and meta-analysis. Int Dent J. 2017;67(6):332-43.

37. Axelsson P, Nystrom B, Lindhe J. The long-term effect of a plaque control program on tooth mortality, caries and periodontal disease in adults. Results after 30 years of maintenance. J Clin Periodontol. 2004;31(9):749-57.

38. Ylostalo P, Suominen-Taipale L, Reunanen A, Knuuttila M. Association between body weight and periodontal infection. J Clin Periodontol. 2008;35(4):297-304

\section{Publisher's Note}

Springer Nature remains neutral with regard to jurisdictional claims in published maps and institutional affiliations.
Ready to submit your research? Choose BMC and benefit from:

- fast, convenient online submission

- thorough peer review by experienced researchers in your field

- rapid publication on acceptance

- support for research data, including large and complex data types

- gold Open Access which fosters wider collaboration and increased citations

- maximum visibility for your research: over $100 \mathrm{M}$ website views per year

At BMC, research is always in progress.

Learn more biomedcentral.com/submissions 